\title{
Article
}

\section{Effect of Annealing in ITO Film Prepared at Various Argon-and-Oxygen-Mixture Ratios via Facing-Target Sputtering for Transparent Electrode of Perovskite Solar Cells}

\author{
Yujin Kim ${ }^{1}$, Sung Hwan Joo ${ }^{1}$, Seong Gwan Shin ${ }^{2} \mathbb{D}$, Hyung Wook Choi ${ }^{1}$, Chung Wung Bark ${ }^{1} \mathbb{D}$, \\ You Seung Rim ${ }^{2, * \mathbb{D}}$, Kyung Hwan Kim ${ }^{1, *}$ and Sangmo Kim ${ }^{2, *}$ \\ 1 Department of Electrical Engineering, Gachon University, Seongnam 13120, Korea; \\ yuzin0416@gmail.com (Y.K.); tjdghksd1080@naver.com (S.H.J.); chw@gachon.ac.kr (H.W.C.); \\ bark@gachon.ac.kr (C.W.B.) \\ 2 Department of Intelligent Mechatronics Engineering and Convergence Engineering for Intelligent Drone, \\ Sejong University, Seoul 05006, Korea; 1020days@gmail.com \\ * Correspondence: youseung@sejong.ac.kr (Y.S.R.); khkim@gachon.ac.kr (K.H.K.); \\ sangmokim@sejong.ac.kr (S.K.)
}

check for updates

Citation: Kim, Y.; Joo, S.H.; Shin, S.G.; Choi, H.W.; Bark, C.W.; Rim, Y.S.;

Kim, K.H.; Kim, S. Effect of Annealing in ITO Film Prepared at Various Argon-and-Oxygen-Mixture Ratios via Facing-Target Sputtering for Transparent Electrode of

Perovskite Solar Cells. Coatings 2022, 12, 203. https://doi.org/10.3390/ coatings12020203

Academic Editor: Alessandro Latini

Received: 28 December 2021

Accepted: 31 January 2022

Published: 4 February 2022

Publisher's Note: MDPI stays neutral with regard to jurisdictional claims in published maps and institutional affiliations.

Copyright: (C) 2022 by the authors. Licensee MDPI, Basel, Switzerland. This article is an open access article distributed under the terms and conditions of the Creative Commons Attribution (CC BY) license (https:// creativecommons.org/licenses/by/ $4.0 /)$.

\begin{abstract}
Normal perovskite solar cells (PSCs) consist of the following layers: transparent electrode, electron-transport layer (ETL), light-absorbing perovskite layer, hole-transport layer (HTL), and metal electrode. Energy, such as electricity, is produced through light absorbance and electronhole generation/transport between two electrode types (metal film and transparent conducting film). Among stacked layers in a PSC, the transparent electrode plays the high-performance-powerconversion-efficiency role. Transparent electrodes should have high-visible-range transparency and low resistance. Therefore, in this study, we prepared indium tin oxide (ITO) films on a glass substrate by using facing-target sputtering without substrate heating treatment and investigate the heatingtreatment effect on the ITO-film properties for perovskite solar cells (PSCs). Moreover, we fabricated PSCs with ITO films prepared at various oxygen flows during the sputtering process, and their energy-conversion properties are investigated.
\end{abstract}

Keywords: transparent electrode; sputtering deposition; oxygen gas; PSCs

\section{Introduction}

During the last decade, interest in renewable energy has been increasing due to environmental problems, such as global warming, air pollution, and conventional-energyresource depletion. Among a variety of renewable-energy sources, energy, such as electricity generation through photovoltaics (PVs), has dominated the alternative-energy market [1]. Conventional solar cells can convert sunlight into electrical energy between the metal and transparent conducting electrodes, which are connected to the load [2].

Meanwhile, organic-metal halide perovskite solar cells (PSCs) have surpassed the power conversion efficiency (PCE) record, exceeding 25\% to date within a few years. The PSC has a sandwich structure between the metal and transparent electrode. Reflection, absorption, resistive losses, and lost active area, either from the scribed interconnect region in monolithically integrated modules or from the shadow losses of a metal grid in standard modules, typically reduce the efficiency by $10-25 \%[3,4]$.

Compared to the internal layers, the counter electrode in the device, the transparent conducting (TC) layer in a solar cell has a significant impact on the power conversion efficiency. To date, PSCs have been employed with fluorine-doped tin oxide (FTO)coated glass substrates as transparent electrodes, owing to annealing at high temperatures over $450{ }^{\circ} \mathrm{C}$ for the $\mathrm{TiO}_{2}$ layer. The $\mathrm{TiO}_{2}$ layer is responsible for collecting photogenerated electrons in the perovskite layer upon light illumination and then transferring it to the electrode $[5,6]$. 
Instead of FTO electrodes, transparent conducting materials have been introduced as potential materials, such as indium tin oxide (ITO) or metal-doped zinc oxide ( $\mathrm{ZnO})$, which have high conductivity and low absorptivity in the visible range. Among them, ITO have been well known for excellent electrical and optical properties [7,8]. Meanwhile, ITO-film fabrication process usually requires a high annealing temperature $\left(>300{ }^{\circ} \mathrm{C}\right)$ at high vacuum environment to get high-quality ITO film as $\mathrm{Sn}^{4+}$ is substituted for $\mathrm{In}^{3+}$. Due to the process conditions, ITO usually is not compatible with most applications based on plastic substrates [9]. Moreover, ITO also has weak points that may limit the potential electrical applications due to the issue of high-temperature stability in the device-fabrication process [10].

In this study, our purpose is to replace the transparent electrode with ITO instead of FTO while overcoming disadvantages of conventional ITO. We employed ITO with facingtarget sputtering (FTS), which is well known for low-damage sputtering and high-quality film growth [11], for film preparation. All films were deposited without substrate heating during the sputtering process. In addition, we controlled the ITO film's electrical and optical properties during the film-sputtering process with oxygen-gas flow. We deposited ITO films on glass substrates via FTS and fabricated PSCs with as-prepared ITO films. The as-prepared ITO films were post-annealed at a temperature of $480{ }^{\circ} \mathrm{C}$, and their properties were investigated for use as transparent electrodes in PSCs. Finally, we investigated the influence of ITO films on solar cells.

\section{Experimental Details}

\subsection{Sputtering Conditions and ITO-Film Coating}

Before depositing the ITO film, the soda-lime glass (Eagle XG glass) substrates were ultrasonically cleaned using acetone, ethanol, and DI water for $20 \mathrm{~min}$ to remove any remaining substrate-surface impurities. Any remaining substrate impurities were blown off using pure nitrogen gas and dried in a dry oven at $80^{\circ} \mathrm{C}$. More-detailed ITO-filmsputtering conditions are presented in Table 1 . We purchased commercial ITO targets $(240 \mathrm{~mm} \times 40 \mathrm{~mm})$ from RND Korea Company. The sputtering process was maintained at $1.5 \times 10^{-5}$ Torr, and film sputtering was conducted at a working gas (Ar and $\mathrm{O}_{2}$ mixture) pressure of $1 \mathrm{mTorr}$ with MFC controller. To remove target impurities, presputtering was performed for $10 \mathrm{~min}$, and then main sputtering was performed for thin-film production at room temperature. The post-annealing process was conducted after ITO-coated glass substrates were transferred to a furnace.

Table 1. Sputtering conditions of ITO film.

\begin{tabular}{cc}
\hline Parameter & Detailed Conditions \\
\hline Targets & $\mathrm{ITO}\left(\mathrm{In}_{2} \mathrm{O}_{3}: \mathrm{Sn}_{2} \mathrm{O}_{3}=90: 10 \mathrm{wt} \%\right)$ \\
Substrate & Soda-lime glass (Eagle XG glass) \\
Bass pressure & $1.5 \times 10^{-5} \mathrm{Torr}$ \\
Working pressure & $1 \mathrm{mTorr}$ \\
Working gas & $\mathrm{Ar}=10 \mathrm{sccm}, \mathrm{O}_{2}=0-0.6 \mathrm{sccm}$ \\
Input power & $500 \mathrm{~W}\left(0.04 \mathrm{~W} / \mathrm{cm}^{2}\right)$ \\
Substrate temperature & Room temperature \\
Film thickness & 200 nm \\
Post-annealing & $480{ }^{\circ} \mathrm{C}(1 \mathrm{~h})$ without vacuum \\
\hline
\end{tabular}

\subsection{Chemical Materials and Fabrication for Perovskite Solar Cells (PSCs)}

For fabricating the devices, we purchased other chemicals, such as titanium diisopropoxide bis(acetylacetone) (75 $\mathrm{wt} \%$ in isopropanol, Sigma-Aldrich), 1-butyl alcohol (99\%, Sigma-Aldrich), $\mathrm{TiO}_{2}$ paste (18 NR-T, Greatcell Solar), N,N-dimethylformamide (DMF, 99.8\%, Sigma-Aldrich), dimethyl sulfoxide (DMSO, $\geq 99.9 \%$, Sigma-Aldrich), ethyl alcohol ( $\geq 99.5 \%$, Sigma-Aldrich), chlorobenzene (99.8\%, Sigma-Aldrich), lead(II) iodide (99.999\% trace metals basic, Sigma-Aldrich), formamidinium iodide (FAI, Greatcell Solar, Aus- 
tralia), methylammonium hydrochloride ( $\mathrm{MACl}$, Greatcell Solar, Australia), toluene (99.9\%, Sigma-Aldrich), 2,2' $, 7,7^{\prime}$-tetrakis[N,N-di(4-methoxyphenyl)amino]-9,9'-spirobifluorene (spiroOMeTAD, 99\%, Sigma-Aldrich), bis(trifluoromethane)-sulfonimide lithium salt (Li-TSFI; $\geq 99.0 \%$, Sigma-Aldrich), acetonitrile (99.93\%, Sigma-Aldrich), and 4-tert-butylpyridine ( $98 \%$, Sigma-Aldrich). All reagents were used as received without further purification. FTO-coated glass (FCG, sheet resistance $7 \Omega /$ sq, Wooyang GMS) and ITO-coated glass were used as the substrates. Conventional ITO-coated substrates (C-ITO, sheet resistance $8 \Omega /$ sq) were purchased from RND Korea Company.

Spin coating was performed for preparing layers (one step) for PSCs [12,13] and the fabrication process is schematically shown in Figure 1.
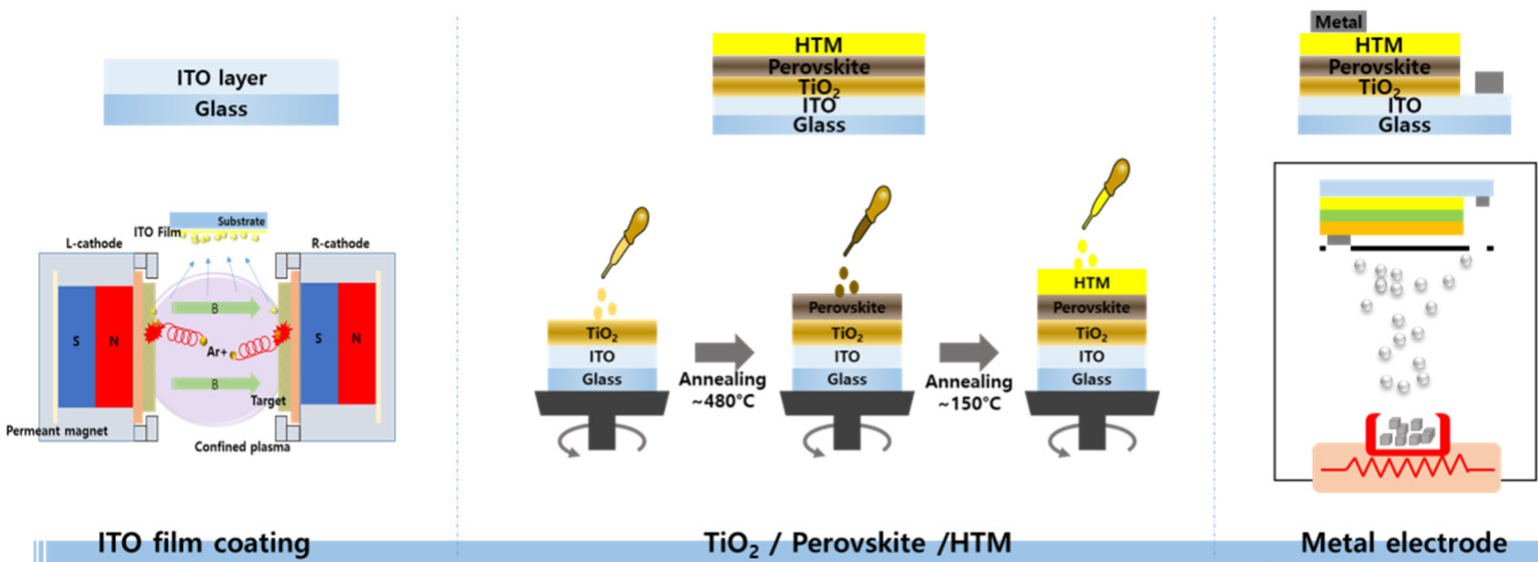

Figure 1. Schematics of perovskite solar cells (PSCs) with ITO-film-fabrication procedure.

A metal electrode (Au, 4N, Kojundo Chemical Laboratory) was deposited using a thermal evaporator. The substrates were sequentially washed with acetone, ethanol, and deionized water for $15 \mathrm{~min}$ each in an ultrasonic bath. To deposit the compact- $\mathrm{TiO}_{2}\left(\mathrm{c}-\mathrm{TiO}_{2}\right)$ layer, $55 \mathrm{~mL}$ of a titanium diisopropoxide bis(acetylacetonate)/1-butyl alcohol (1:10 v/v) solution was spin coated at $3000 \mathrm{rpm}$ for $30 \mathrm{~s}$. The substrate was then heated at $120{ }^{\circ} \mathrm{C}$ for $15 \mathrm{~min}$. On top of the $\mathrm{c}-\mathrm{TiO}_{2}$ layer, a mesoporous- $\mathrm{TiO}_{2}\left(\mathrm{mp}-\mathrm{TiO}_{2}\right)$ layer was spin coated at $3000 \mathrm{rpm}$ for $30 \mathrm{~s}$. The $\mathrm{mp}-\mathrm{TiO}_{2}$ paste with an average nanoparticle size of $20 \mathrm{~nm}$ was dispersed in ethyl alcohol $(1: 6 w / w)$. The prepared $\mathrm{FTO} / \mathrm{c}-\mathrm{TiO}_{2} / \mathrm{mp}-\mathrm{TiO}_{2}$ substrates were calcined at $500{ }^{\circ} \mathrm{C}$ for $1 \mathrm{~h}$ and then cooled to room temperature. To fabricate the perovskite layer, the $1.4 \mathrm{~mol}$ of perovskite solution was prepared by mixing $\mathrm{FAI}$ and $\mathrm{PbI}_{2}$ in a mixture of DMF and DMSO $(8: 1 v / v)$. Subsequently, MACl was added to the prepared precursor solution. The perovskite layer was spin coated onto the $\mathrm{mp}-\mathrm{TiO}_{2}$ layer at $4000 \mathrm{rpm}$ for $20 \mathrm{~s}$. During spin coating, $200 \mu \mathrm{L}$ of toluene was added dropwise using a pipette after spinning for $10 \mathrm{~s}$. The film was heated on a hot plate at $150{ }^{\circ} \mathrm{C}$ for $10 \mathrm{~min}$. The hole-transport layer was prepared using Spiro-OMeTAD in chlorobenzene $(72.3 \mathrm{mg} / \mathrm{mL})$, and $28.8 \mu \mathrm{L}$ 4-tertbutyl pyridine and $17.5 \mu \mathrm{L}$ Li-bis solution (520 mg Li-TFSI/1 mL acetonitrile) were added. Finally, a $60 \mathrm{~nm}$ thick gold electrode was deposited using a thermal evaporation system.

\subsection{Characteristic Measurements}

The basic characteristics of the ITO films prepared according to oxygen-gas flow were analyzed using the following analysis devices. The electrical properties of the films were measured using a Hall effect measurement system (HL5500PC, Accent Optical Technologies, Hemel Hempstead, UK). Their optical transmittance was analyzed using UV-vis spectroscopy (LAMBDA 750, PerkinElmer, Walthanm, MA, USA). The crystallographic structural properties of the as-prepared films were determined by $\mathrm{X}$-ray diffraction (SmartLab, Rigaku, Tokyo, Japan) using $\mathrm{Cu}-\mathrm{K} \alpha$ radiation $(\lambda=1.54056 \AA, 40 \mathrm{kV}, 40 \mathrm{~mA})$ in the $2 \theta$ scan mode. The film morphology and PSC cross sections were obtained using field- 
emission SEM (FE-SEM, Hitachi S-4700, Tokyo, Japan). To evaluate the performance of the PSC device, we checked the current-voltage (J-V) curves of the devices using a solar simulator (Polaromix K201 \& McScience K3000, McScience, Gyeonggi-do, Korea). under 1 sun illumination (AM1.5G, $100 \mathrm{~mW} / \mathrm{cm}$ ).

\section{Results and Discussion}

\subsection{Film Characteristics}

\subsubsection{Electrical Characteristics}

First, we checked the ITO-film properties after finishing film sputtering. Then, the asprepared ITO films were post-annealed at a temperature of $480{ }^{\circ} \mathrm{C}$ (the heating temperature for the $\mathrm{TiO}_{2}$ layer in PSC-device fabrication) in air, and the films were measured. Figure 2 shows the electrical properties (resistivity, carrier concentration, and mobility) of the nonannealed and post-annealed ITO films at $480^{\circ} \mathrm{C}$.

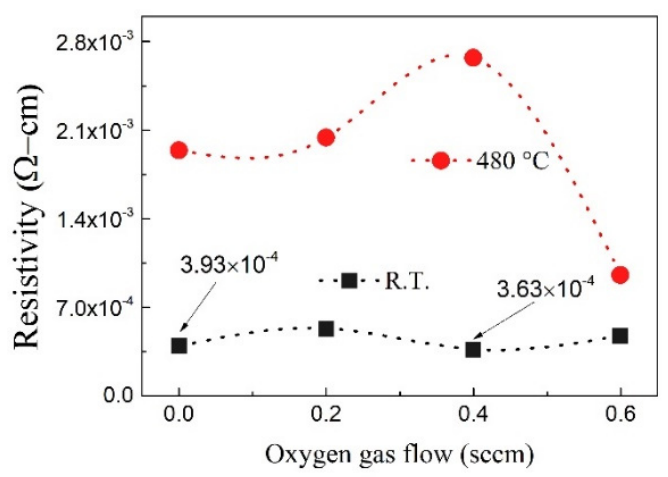

(a)

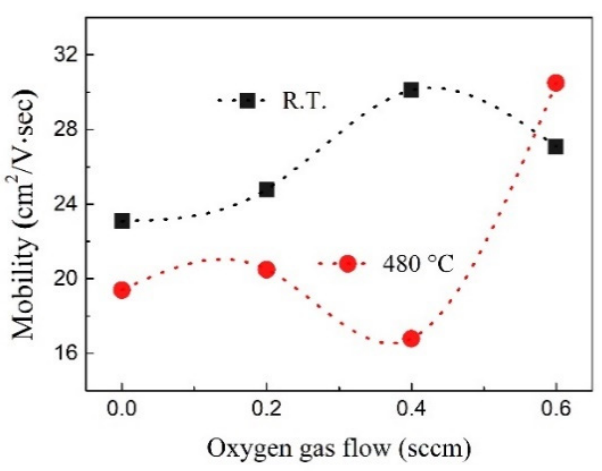

(b)

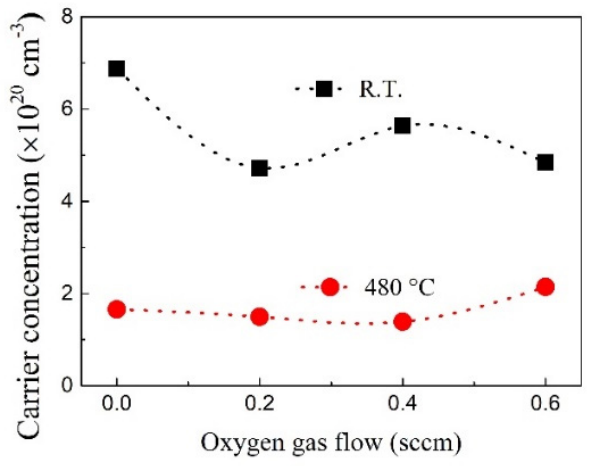

(c)

Figure 2. Electrical properties of ITO films. The following are functions of oxygen-gas flow without postannealing and with post-annealing at $480^{\circ} \mathrm{C}$ : (a) resistivity, (b) mobility, and (c) carrier concentration.

As the oxygen-gas flow with non-annealing increased, the lowest resistivity was $3.63 \times 10^{-4} \Omega$-cm (sheet resistance $18.38 \Omega / \mathrm{sq}$ ) at $0.4 \mathrm{sccm}$ of oxygen-gas flow $\left(\mathrm{O}_{2} /\left(\mathrm{Ar}+\mathrm{O}_{2}\right)\right.$ gas ratio $0.04 \%$ ). When the oxygen-gas flow was increased to $0.2 \mathrm{sccm}$, the resistivity increased to $5.33 \times 10^{-4} \Omega$-cm. For mobility of the ITO film with non-annealing, it increased from 23.1 to $30.1 \mathrm{~cm}^{2} / \mathrm{V} \cdot \mathrm{s}$ with increasing oxygen gas but decreased by $28 \mathrm{~cm}^{2} / \mathrm{V} \cdot \mathrm{s}$ at $0.5 \mathrm{sccm}$ owing to scattering of electrons by atomic oxygen originated from inserted oxygen gas. In other words, as the Sn concentration was constant and the oxygen-gas flow increased, the number of oxygen vacancies decreased, so the free-carrier concentration decreased. Mobility increases because the film-oxygen-vacancy content, which plays a role in interfering with electron mobility, is reduced. If oxygen is excessively supplied, oxygen vacancies cannot generate carriers, resulting in a decrease in carrier concentration and an increase in resistivity $[14,15]$. Carrier concentration decreased from $6.88 \times 10^{20}$ to 
$5.64 \times 10^{20} \mathrm{~cm}^{-3}$ by $0.4 \mathrm{sccm}$. The primary ITO carrier is the electron, and the electron is generated by the substitution of oxygen vacancy and $\mathrm{Sn}^{4-}$ with $\mathrm{In}^{3+}$ [16].

ITO films with post-annealing, that is, at $480{ }^{\circ} \mathrm{C}$, showed a similar trend to that of oxygen-gas flow, as shown in Figure 2. After the ITO films were post-annealed in air, all samples showed poorer electrical properties, owing to the rich oxygen gas in the atmosphere, compared with ITO films without annealing. The electrical properties of all films can be controlled by inserting an oxygen-gas flow. The resistivity, mobility, and carrier concentration are affected by each other in all ITO films, regardless of the heat treatment.

\subsubsection{Optical Properties}

Figure 3 shows optical transmittance of the ITO thin film deposited at the various oxygen-flow rates in the visible range of $370-760 \mathrm{~nm}$. The optical properties of all ITO films demonstrated over $80 \%$ of optical transmittance. As the amount of oxygen input increases, the ITO-carrier concentration without post-annealing decreases from $6.88 \times 10^{20}$ to $4.88 \times 10^{20} \mathrm{~cm}^{-3}$ (Figure 2) and reduces the absorption and scattering of light, improving the transmittance, as shown in Figure 3 a.

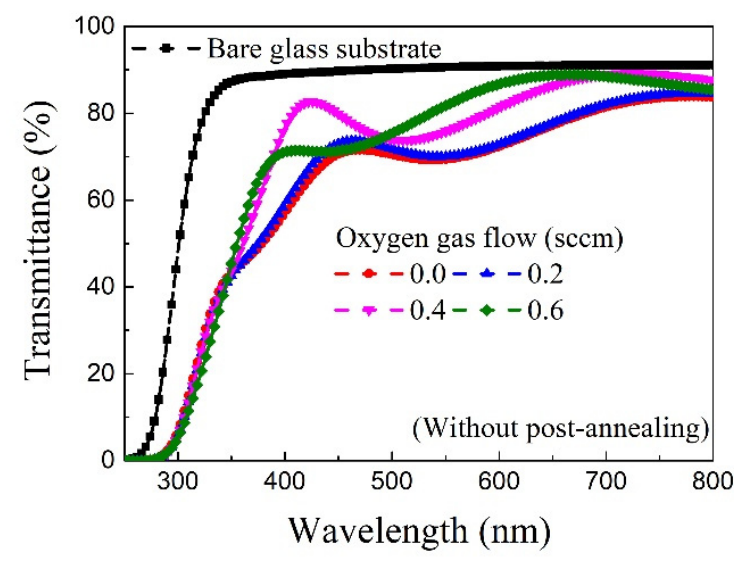

(a)

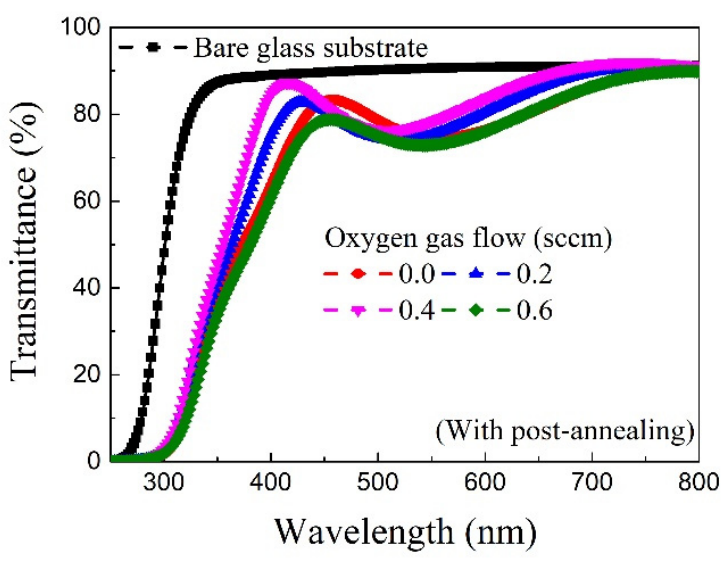

(c)

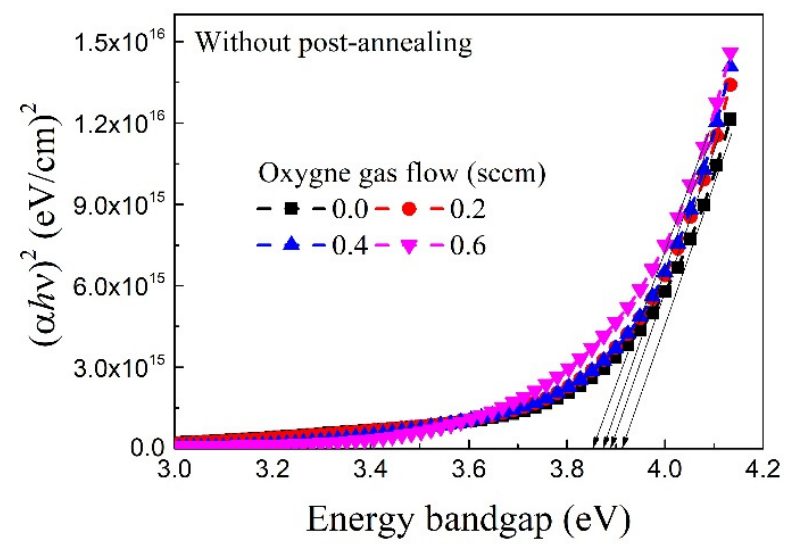

(b)

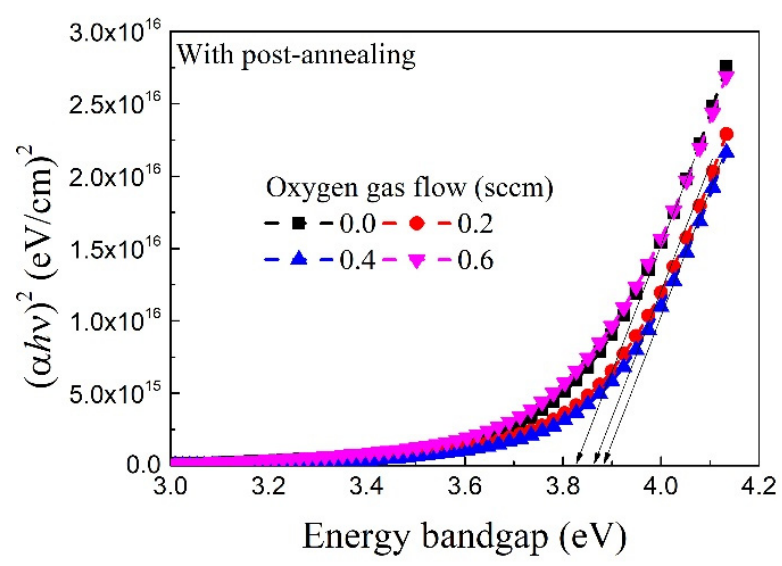

(d)

Figure 3. Optical transmittance and energy bandgap of ITO films as a function of wavelength at various rates of oxygen-gas flow $(\mathbf{a}, \mathbf{b})$ without post-annealing and $(\mathbf{c}, \mathbf{d})$ with post-annealing at $480{ }^{\circ} \mathrm{C}$.

After post-annealing, the optical transmittance of the ITO films was enhanced significantly, as shown Figure 3b, owing to the oxidation reaction with sufficient oxygen gas in the air. The optical transmittance of the post-annealed films was confirmed to be due to improvement in crystalline behavior (Figure 4 and Table 2). The films annealed at $480{ }^{\circ} \mathrm{C}$ might be ascribed to the ordered structure and calculated grain-size-corresponding (222) peak [17]. 


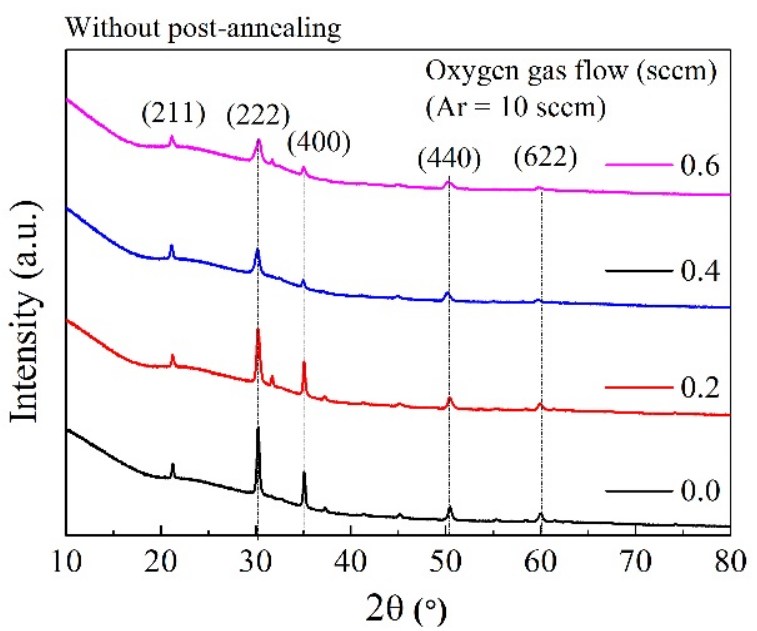

(a)

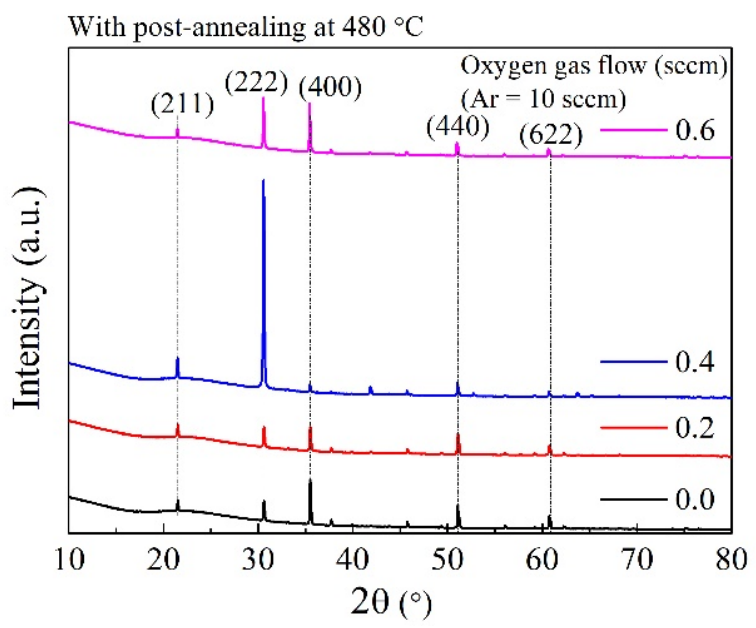

(b)

Figure 4. XRD patterns of ITO films prepared at various rates of oxygen-gas flow (a) without post-annealing and (b) with post-annealing at $480{ }^{\circ} \mathrm{C}$.

Table 2. Summary of properties for (222) in ITO films.

\begin{tabular}{|c|c|c|c|c|c|c|c|}
\hline $\begin{array}{c}\text { Heating } \\
\text { Condition }\end{array}$ & $\begin{array}{c}\text { Gas Flow }{ }^{1} \\
(\mathrm{sccm})\end{array}$ & $\begin{array}{c}R^{2} \\
\left(\times 10^{-4} \Omega-\mathrm{cm}\right)\end{array}$ & $\begin{array}{c}R_{\text {sheet }}{ }^{3} \\
(\Omega / s q)\end{array}$ & $\begin{array}{c}\mu^{4} \\
\left(\times 10^{20} \mathrm{~cm}^{-3}\right)\end{array}$ & $\begin{array}{c}\mathrm{N}^{5} \\
\left(\mathrm{~m}^{2} / \mathrm{V} . \mathrm{s}\right)\end{array}$ & $\begin{array}{c}\text { FWHM }^{6} \\
\left({ }^{\circ}\right)\end{array}$ & $\begin{array}{c}\text { Grain Size } \\
(\mathrm{nm})\end{array}$ \\
\hline \multirow{4}{*}{ None } & 0.0 & 3.93 & 19.67 & 6.88 & 23.1 & 0.2832 & 30.2 \\
\hline & 0.2 & 5.33 & 26.67 & 4.722 & 24.8 & 0.3620 & 23.7 \\
\hline & 0.4 & 3.67 & 18.38 & 5.635 & 30.1 & 0.2600 & 40.9 \\
\hline & 0.6 & 4.76 & 23.8 & 4.842 & 27.1 & 0.2600 & 18.1 \\
\hline \multirow{4}{*}{$480^{\circ} \mathrm{C}$} & 0.0 & 19.4 & 97.05 & 1.656 & 19.4 & 0.0875 & 98.3 \\
\hline & 0.2 & 20.4 & 102.1 & 1.494 & 20.5 & 0.0991 & 86.2 \\
\hline & 0.4 & 26.7 & 133.6 & 1.387 & 16.8 & 0.1113 & 77.3 \\
\hline & 0.6 & 9.55 & 47.76 & 2.142 & 30.5 & 0.1113 & 96.0 \\
\hline
\end{tabular}

${ }^{1}$ Gas flow is oxygen in pure argon gas on sputtering. ${ }^{2} \mathrm{R}$, resistivity; ${ }^{3} \mathrm{R}_{\text {sheet }}$, sheet resistance; ${ }^{4} \mu$, carrier concentration; ${ }^{5} \mathrm{~N}$, mobility; ${ }^{6} \mathrm{FWHM}$, full width at half maximum; grain size of films was calculated in (220) peaks of XRD.

In addition, the absorption edge shifted toward higher wavelengths with increasing oxygen gas. In other words, the red-shift phenomenon was shown.

To determine the possibility of a transparent device, the energy band gap was calculated, and the following equation was used to obtain the energy band gap $\left(\mathrm{E}_{\mathrm{g}}\right)$ [18].

$$
(\alpha \mathrm{h} v)^{2}=\mathrm{A}\left(\mathrm{h} v-\mathrm{E}_{\mathrm{g}}\right)^{1 / 2}
$$

where $\mathrm{A}$ is a constant, $\mathrm{h}$ is the Planck constant, $v$ is the photon frequency, and $\mathrm{E}_{\mathrm{g}}$ is the optical band gap. It can be seen that when the oxygen-flow rate increases, the carrier concentration decreases and the energy band gap decreases from 3.92 to $3.61 \mathrm{eV}$ (for ITO films without post-annealing) and from 3.9 to 3.82 (for ITO films with post-annealing) as shown in Figure 3b,d.

\subsubsection{Structural Properties}

Figure 4 shows the structural properties of the ITO thin film according to the oxygen flow and heating treatment using the XRD diffraction pattern. All films have a polycrystalline structure with observed directional-reflection peaks of (211), (222), (400), (440), and (622), which show that cubic bixbyite (bcc-ITO) films are formed (ICDD No. 01-0833352) [19]. No additional peaks could be observed corresponding to impurity phases. The oxygen and heating treatment effects on the ITO-film peak intensity is clearly observed in the XRD spectrum in Figure 4. 
It can be concluded that there is a general increase in the peak intensities with the oxygen-gas flow. Similarly, the reflections, such as (211), (400), and (440), are due to the oxygen concentration in the film sputtering. There is strong evidence that for the oxygen concentration, the (222) peak is the preferred growth orientation for ITO films. The presence of oxygen induces the formation of In-O bonding networks and promotes the growth of the $(222)[19,20]$. However, their peak intensities decreased in the ITO-film XRD pattern processed in an oxygen-rich environment $(0.6 \mathrm{sccm})$. In the case of the ITO film with post-annealing, all films are polycrystalline with a preferentially oriented (222) plane, and the (400) decreases with increasing oxygen-gas concentration. It has been reported that when ITO thin films grow, the growth (222) is caused by high-oxygen concentration or temperature, and growth is inhibited in the (440) direction $[18,19]$. To analyze the grain size according to the oxygen-flow rate, the full width at half maximum (FWHM) was obtained from the direction of growth (222) and calculated using Scherrer's formula [20].

$$
\mathrm{D}=\frac{0.9 \lambda}{\beta \operatorname{Cos} \theta}
$$

where $\theta$ is the Bragg diffraction angle, $\beta$ is the FWHM, D is the grain size, and $\lambda$ is the X-ray wavelength of $1.5406 \AA$. Electrical properties, FWHM, and grain size are summarized in Table 2. As the oxygen-gas flow increased, the fouling width decreased from 0.2832 to $0.2600^{\circ}$ and the grain size decreased from 30.29 to $19.1 \mathrm{~nm}$. The increase in grain size is the cause of the decrease in scattering, and the transmittance increases, as shown in Figure 4 , as the oxygen flow rate increases [21].

After post-annealing, we believe that the ITO crystal properties are improved by ITO films without annealing. After post-annealing, the electrical properties of the ITO films were enhanced by increasing the film grain sizes, as shown in Table 2.

Even though the crystallization of film improved with increasing temperature, both amount of the mobility and carrier concentration (mainly as density of $\mathrm{Sn}^{4+}$ carriers) dropped, thereby increasing the resistance [22].

As above mentioned, the improvement in the crystalline structure of film can be expected because post-annealed films have larger amounts of interstitial oxygen atoms in the film through growth direction along with the (222) plane [23]. The trend causes decreasing on the film's band gap, and narrowing of the energy band gap with postannealing treatment could be attributed to the possibilities of oxidation, more realignment, and strong interaction between film and substrate [24].

\subsubsection{PV Properties of Unit Cell with ITO Films}

Based on the above results, we fabricated PSCs with ITO films for each oxygen-gas concentration, and the samples' energy-conversion performances are shown in Figure 5. More detailed measurements are presented in Table 3.

It can be seen that the energy-power conversion depends on the oxygen concentration of the ITO films. The PSCs (Sample \#1) with ITO films prepared in an environment of pure argon gas have the best performance over other samples due to the low resistivity after $480{ }^{\circ} \mathrm{C}$ heating treatment. Its PSCs had JSC $24.823 \mathrm{~mA} / \mathrm{cm}^{2}$, F.F. $60.711 \%, \mathrm{~V}_{\mathrm{OC}} 0.12 .804 \mathrm{~V}$, and an efficiency of $13.904 \%$ (average values). After the oxygen-gas flow was increased, the PSC PV properties showed at least $50 \%$ of improved performance compared with the PSCs with the ITO film prepared with pure argon gas. After $0.6 \mathrm{sccm}$ of oxygen gas was flowing, the PSC PV properties (Sample \#4) increased, owing to their electrical properties. 


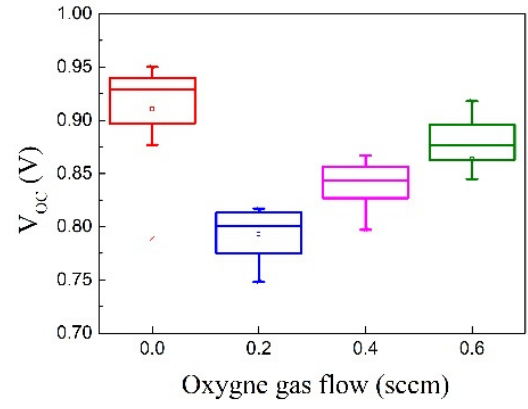

(a)

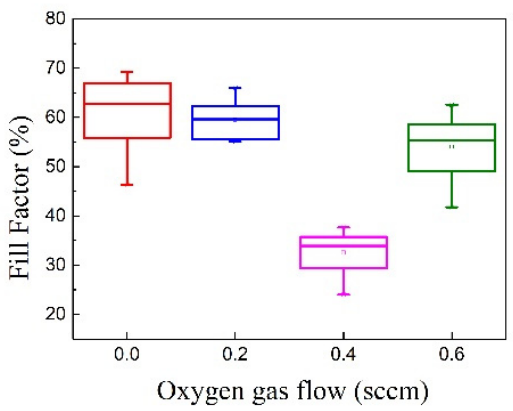

(c)

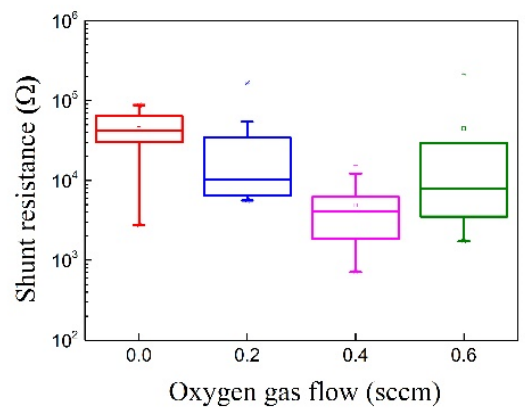

(e)

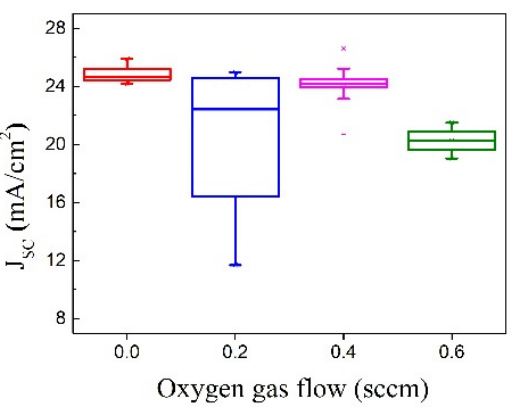

(b)

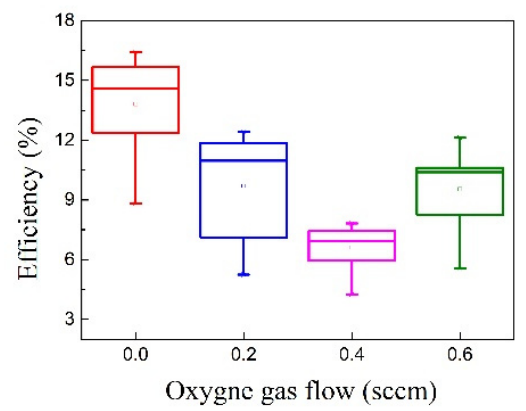

(d)

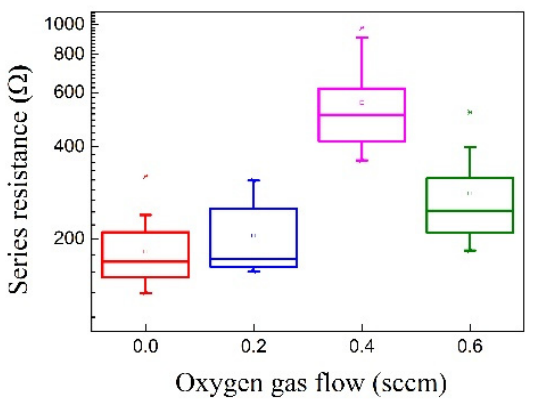

(f)

Figure 5. Comparison of PV properties for prepared PSCs with ITO films as a function of oxygen-gas flow: (a) open-circuit voltage, (b) short-circuit current density, (c) fill factor, (d) power conversion efficiency, (e) shunt resistance, and (f) series resistance of prepared PSC devices.

Table 3. Photovoltaic-performance parameters of PSCs with various TCO materials.

\begin{tabular}{|c|c|c|c|c|c|c|c|}
\hline $\begin{array}{c}\text { Sample } \\
\text { (Condition) }\end{array}$ & $\begin{array}{c}\mathrm{V}_{\mathrm{OC}}^{\mathrm{a}} \\
(\mathrm{V})\end{array}$ & $\begin{array}{l}I_{S C} b \\
(m A)\end{array}$ & $\begin{array}{c}\mathrm{JSC}^{\mathrm{c}} \\
\left(\mathrm{mA} / \mathrm{cm}^{2}\right)\end{array}$ & $\begin{array}{l}\text { F.F. }{ }^{d} \\
(\%)\end{array}$ & $\begin{array}{c}\text { PCE e } \\
(\%)\end{array}$ & $\begin{array}{c}\mathbf{R}_{\text {Shunt }} \\
(\Omega)\end{array}$ & $\begin{array}{c}R_{\text {Series }} \\
(\Omega)\end{array}$ \\
\hline$\# 1$ & 0.910 & 1.13 & 24.82 & 62.71 & 13.81 & $4.4 \mathrm{k}$ & 181.15 \\
\hline$(0.0 \mathrm{sccm})$ & $( \pm 0.045)$ & $( \pm 0.027)$ & $( \pm 0.507)$ & $( \pm 7.346)$ & $( \pm 2.336)$ & $( \pm 2.4 \mathrm{k})$ & $( \pm 47.05)$ \\
\hline \#2 & 0.793 & 1.08 & 20.44 & 59.53 & 9.69 & $3.4 \mathrm{k}$ & 204.35 \\
\hline$(0.2 \mathrm{sccm})$ & $( \pm 0.023)$ & $( \pm 0.270)$ & $( \pm 5.086)$ & $( \pm 3.693)$ & $( \pm 2.666)$ & $( \pm 5.1 \mathrm{k})$ & $( \pm 55.95)$ \\
\hline \#3 & 0.839 & 1.27 & 24.12 & 32.54 & 6.61 & $4.8 \mathrm{k}$ & 556.37 \\
\hline$(0.4 \mathrm{sccm})$ & $( \pm 0.018)$ & $( \pm 0.059)$ & $( \pm 1.114)$ & $( \pm 4.254)$ & $( \pm 1.026)$ & $( \pm 3.6 \mathrm{k})$ & $( \pm 173.38)$ \\
\hline$\# 4$ & 0.863 & 1.07 & 20.29 & 53.98 & 9.55 & $4.4 \mathrm{k}$ & 281.38 \\
\hline$(0.6 \mathrm{sccm})$ & $( \pm 0.057)$ & $( \pm 0.038)$ & $( \pm 0.722)$ & $( \pm 5.91)$ & $( \pm 1.735)$ & $( \pm 7.08 \mathrm{k})$ & $( \pm 92.07)$ \\
\hline \multirow[t]{2}{*}{ C-FTO } & 0.935 & 1.04 & 19.36 & 68.36 & 12.56 & $5.9 \mathrm{k}$ & 139.09 \\
\hline & $( \pm 0.018)$ & $( \pm 0.02)$ & $( \pm 0.372)$ & $( \pm 2.338)$ & $( \pm 0.617)$ & $( \pm 7.3 \mathrm{k})$ & $( \pm 21.21)$ \\
\hline \multirow[t]{2}{*}{ C-ITO } & 0.783 & 0.903 & 17.05 & 23.69 & 2.90 & $0.97 \mathrm{~K}$ & 1618.4 \\
\hline & $( \pm 0.135)$ & $( \pm 0.2)$ & $( \pm 3.783)$ & $( \pm 8.917)$ & $( \pm 0.833)$ & $( \pm 508.6)$ & $( \pm 1060.2)$ \\
\hline
\end{tabular}

${ }^{a}$ Open-circuit voltage, ${ }^{b}$ short-circuit current, ${ }^{\mathrm{c}}$ short-circuit current density, ${ }^{\mathrm{d}}$ fill factor, and ${ }^{\mathrm{e}}$ power conversion efficiency. All values are average values in individual 15 cells. In brackets are standard deviation values. C-FTO is commercial FTO substrate. C-ITO is commercial ITO-coated substrate. 
In Figure 5e,f, the shunt and series resistances of the prepared PSC device depend on the ITO-film electrical properties. This means that the high band gap elements interfere with the electron movement, and the electron movement distance increases [24,25] The resistivity depends on the fill factor (FF), and FF is related to the solar cell resistance as follows [26]:

$$
\begin{gathered}
\mathrm{FF}_{(\text {Sh. R. })}=\mathrm{FF}_{0}\left[1-\frac{1}{\mathrm{R}_{(\text {Sh. R. })}}\right] \\
\mathrm{FF}_{\text {(S.R. })}=\mathrm{FF}_{0}\left[1-\mathrm{R}_{(\text {S.R. })}\right]
\end{gathered}
$$

where $\mathrm{FF}$ is the fill factor and $\mathrm{FF}_{0}$ is the fill factor not affected by any resistance denoted by $\mathrm{I}_{0}$ in the idea cell, Sh.R. is the shunt resistance (resistance in parallel connection), and SR is the series resistance. From the above equations, the FF depends on the shunt and series resistances in normal PSCs. Shunt and series resistances are related to the open-circuit voltage and the short-circuit current, respectively. From the Hall measurement results in Figure 2, it can be concluded that the ITO-film resistance affects the shunt and series resistances inside the cells.

And ITO prepared without oxygen gas is another possible reason for the $\mathrm{V}_{\mathrm{OC}}$ improvement with the MDO, as the top electrode in perovskite devices has more realignment and strong interaction between film and substrate.

In Figure 5, the box plots in each figure indicate the distribution of PV parameters in the inverse- and forward-induced sample data recorded from the solar simulator. Each box includes the maximum, minimum, and average values marked with a line.

We fabricated perovskite solar cells (Figure 6a) separately on commercial FTO (C-FTO), commercial ITO (C-ITO), and ITO film prepared via FTS. The effect of the TCO-material types on the photovoltaic performance of PCS devices is investigated, and current-density-voltage $(\mathrm{J}-\mathrm{V})$ characteristics are displayed in Figure $6 \mathrm{~b}$.
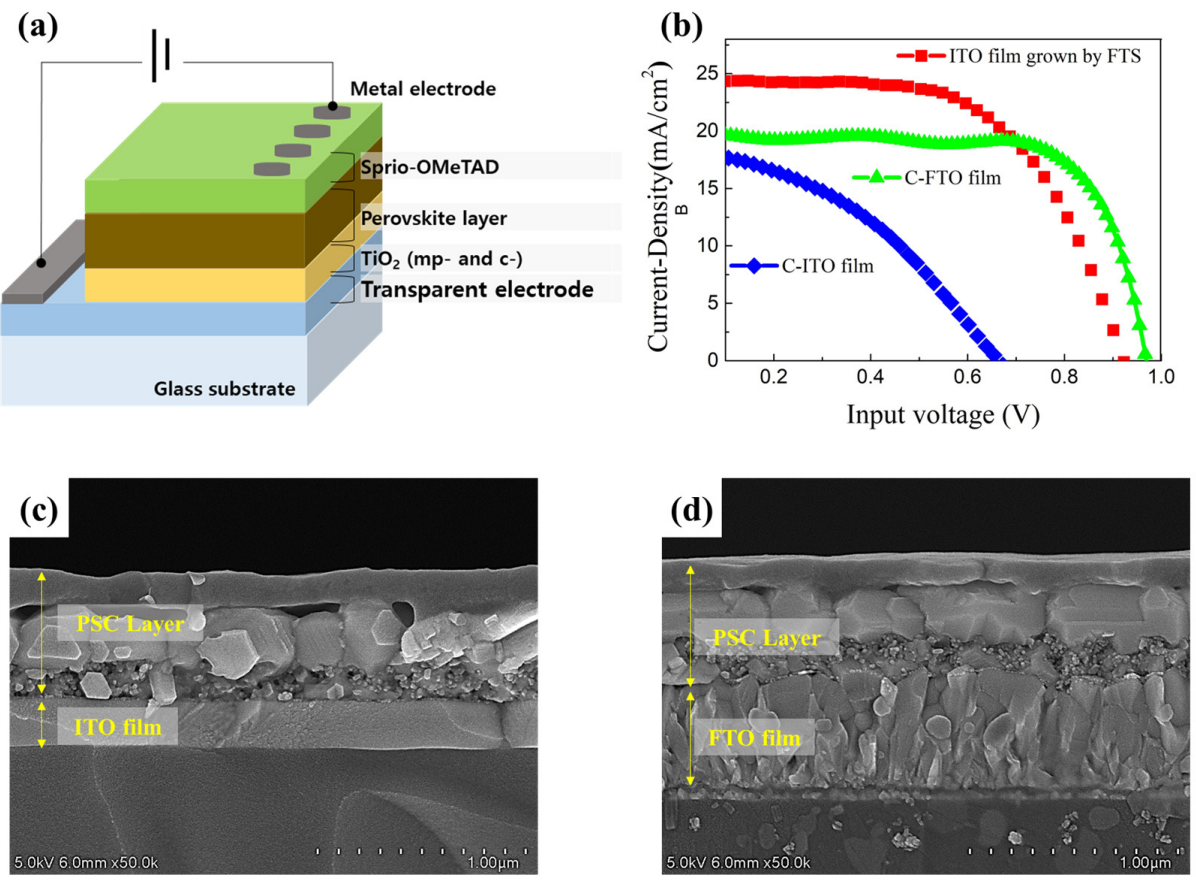

Figure 6. (a) structure of a perovskite solar cell consisting of a transparent conductive oxide (TCO), $\mathrm{TiO} 2$ layer as electron-transport layer (ETL), light-absorbing perovskite materials, spiro-OMeTAD as hole-transport layer (HTL), and Au metal electrode, (b) current density of PSCs with various TCOs (Lab-made ITO, commercial FTO (C-FTO), and commercial ITO (C-ITO)), and cross-sectional FE-SEM images of PSCs with (c) ITO film and (d) FTO film. 
PSC with C-ITO ( 4\%) showed the lowest photovoltaic (PV) performance in three samples. FTS-sputtered ITO films ( 13.8\%) exhibited higher PV performance than commercial C-FTO films $(\sim 12.5 \%)$. All PSC samples are well-constructed with four layers on each TCO-material-coated substrate, as shown in Figure $6 c, d$. We confirmed that ITO film has a smooth surface compared to commercial FTO film. As shown in Figure 6c, the considerably smooth surface of ITO film is contributed to improving the performance of perovskite devices with good alignment and strong interaction between the film and PCS layer during the spin-coating process. Therefore, it is possible that ITO films have the potential to replace FTO as a transparent electrode of PSCs with high-temperature stability.

\section{Conclusions}

We investigate the effects of annealing in ITO film deposited at various argon-andoxygen-mixture ratios via FTS. With increased oxygen-gas flow, the ITO-electrical and -optical properties were improved. After post-annealing was applied to a transparent PSC electrode, resistivity increased two times that of ITO film without heat-treatment annealing. However, the optical transmittance in the visible range improved, and the band gap decreased from 3.9 to 3.82. The PV performance of PSCs depends on ITO films, and PSCs with ITO films prepared with pure argon gas showed the best performance among the samples. Even though PSCs with commercial ITO films have poor energy-conversion efficiency, PSCs with FTS-sputtered ITO films (13.8\%) showed higher PV performance than the commercial FTO films (12.5\%).

We believe that FTS-sputtered ITO films have the potential to replace FTO films as transparent PSC electrodes while overcoming the weaknesses of commercial ITO films.

Author Contributions: Film deposition and original draft preparation, Y.K.; PCS preparation and measurement, S.H.J.; Data analysis, S.G.S.; Experimental supporting, H.W.C.; Data analysis and experimental supporting, C.W.B.; Editing and Supervision, Y.S.R.; Supervision and editing, K.H.K.; Writing and editing, S.K. All authors have read and agreed to the published version of the manuscript.

Funding: This work was funded by the Gachon University Research Fund of 2019 (GCU-2019-20190798) and was also supported by the Technology Innovation Program-(20016102, Development of $1.2 \mathrm{kV}$ Gallium oxide power semiconductor devices technology) funded by MOTIE, Korea.

Institutional Review Board Statement: Not applicable.

Informed Consent Statement: Not applicable.

Data Availability Statement: Not applicable.

Acknowledgments: We thank the Smart Materials Research Center for IoT, supported by NFEC, at Gachon University for its instrumental support (XRD, FE-SEM).

Conflicts of Interest: The authors declare no conflict of interest.

\section{References}

1. Wilson, G.M.; Al-Jassim, M.; Metzger, W.K.; Glunz, S.W.; Verlinden, P.; Xiong, G.; Mansfield, L.M.; Stanbery, B.J.; Zhu, K.; Yan, Y. The 2020 photovoltaic technologies roadmap. J. Phys. D. 2020, 53, 493001. [CrossRef]

2. Polman, A.; Knight, M.; Garnett, E.C.; Ehrler, B.; Sinke, W.C. Photovoltaic materials: Present efficiencies and future challenges. Science 2016, 352, 6283. [CrossRef] [PubMed]

3. Kim, J.Y.; Lee, J.-W.; Jung, H.S.; Shin, H.; Park, N.-G. High-efficiency perovskite solar cells. Chem. Rev. 2020, 120, 7867-7918. [CrossRef]

4. Park, N.-G. Perovskite solar cells: An emerging photovoltaic technology. Mater. Today Commun. 2015, 18, 65-72. [CrossRef]

5. Seok, S.I.; Gratzel, M.; Park, N.-G. Methodologies toward Highly Efficient Perovskite Solar Cells. Small 2018, $14,1704177$. [CrossRef] [PubMed]

6. Markvart, T.; Castañer, L. Principles of solar cell operation. In McEvoy's Handbook of Photovoltaics; Elsevier: London, UK, 2017; pp. 3-28.

7. Micali, M.; Cosentino, S.; Terrasi, A. Structural, optical and electrical characterization of ITO films co-doped with Molybdenum. Sol. Energy Mater Sol. Cells 2021, 221, 110904. [CrossRef] 
8. Buckeridge, J.; Catlow, C.R.A.; Farrow, M.; Logsdail, A.J.; Scanlon, D.; Keal, T.; Sherwood, P.; Woodley, S.; Sokol, A.; Walsh, A. Deep vs shallow nature of oxygen vacancies and consequent $n$-type carrier concentrations in transparent conducting oxides. Phys. Rev. Mater. 2018, 2, 054604. [CrossRef]

9. Zhang, B.; Ng, S.-W.; Lu, L.; Zheng, Z. Solution-Processed Transparent Electrode for Emerging Thin-Film Solar Cells. Chem. Rev. 2020, 120, 2049. [CrossRef]

10. Jung, H.; Kim, G.; Jang, G.S.; Kim, M.; Moon, C.S.; Hao, X.; Jeon, N.J.; Yun, H.S.; Seo, J. Transparent Electrodes with Enhanced Infrared Transmittance for Semitransparent and Four-Terminal Tandem Perovskite Solar Cells. ACS Appl. Mater. Interfaces 2021, 13, 30497. [CrossRef]

11. Kim, S.; Kim, K.H. Effect of magnetic field arrangement of facing targets sputtering (FTS) system on controlling plasma confinement. Coatings 2020, 10, 321. [CrossRef]

12. Im, J.-H.; Kim, H.-S.; Park, N.-G. Morphology-photovoltaic property correlation in perovskite solar cells: One-step versus two-step deposition of CH3NH3PbI3. Apl Mater. 2014, 2, 081510. [CrossRef]

13. Zhang, T.; Xu, Q.; Xu, F.; Fu, Y.; Wang, Y.; Yan, Y.; Zhang, L.; Zhao, Y. Spontaneous low-temperature crystallization of $\alpha$-FAPbI3 for highly efficient perovskite solar cells. Sci. 2019, 64, 1608-1616. [CrossRef]

14. Tuna, O.; Selamet, Y.; Aygun, G.; Ozyuzer, L. High quality ITO thin films grown by de and RF sputtering without oxygen. J. Phys. D 2010, 43, 055402. [CrossRef]

15. Bender, M.; Seelig, W.; Daube, C.; Frankenberger, H.; Ocker, B.; Stollenwerk, J. Dependence of oxygen flow on optical and electrical properties of DC-magnetron sputtered ITO films. Thin Solid Films 1998, 326, 72-77. [CrossRef]

16. Chen, A.; Zhu, K.; Zhong, H.; Shao, Q.; Ge, G. A new investigation of oxygen flow influence on ITO thin films by magnetron sputtering. Sol. Energy Mater Sol. Cells 2014, 120, 157-162. [CrossRef]

17. Ayeshamariam, a.; Kashif, M.; Bououdina, M.; Hashim, U.; Jayachadnran, M.; Ali, M.E. Morphological, structural, and gas-sensing characterization of tin-doped indium oxide nanoparticles. Ceram. Int. 2014, 40, 1321. [CrossRef]

18. Song, S.; Yang, T.; Liu, J.; Xin, Y.; Li, Y.; Han, S. Rapid thermal annealing of ITO films. Appl. Surf. Sci. 2011, 257, 7061-7064. [CrossRef]

19. Ali, A.H.; Hassan, Z.; Shuhaimi, A. Enhancement of optical transmittance and electrical resistivity of post-annealed ITO thin films RF sputtered on Si. Appl. Surf. Sci. 2018, 443, 544-547. [CrossRef]

20. Kulkarni, A.; Schulz, K.H.; Lim, T.; Khan, M. Dependence of the sheet resistance of indium-tin-oxide thin films on grain size and grain orientation determined from X-ray diffraction techniques. Thin solid films 1999, 345, 273-277. [CrossRef]

21. Ahmed, N.N.; Sabah, F.A.; Abdulgafour, H.I.; Alsadig, A.; Sulieman, A.; Alkhoaryef, M. The effect of post annealing temperature on grain size of indium-tin-oxide for optical and electrical properties improvement. Results Phys. 2019, 13, 102159. [CrossRef]

22. Fischbier, M.V.; Wardenga, H.F.; Weidner, M.; Bierwagen, O.; Jia, J.; Shigesato, Y.; Klein, A. Influence of dopant species and concentration on grain boundary scattering in degenerately doped $\operatorname{In}_{2} \mathrm{O}_{3}$ thin films. Thin Solid Films 2016, 614, 62-68. [CrossRef]

23. Lee, J.H.; Kim, Y.H.; Ahn, S.J.; Ha, T.H.; Kim, H.S. Grain-size effect on the electrical properties of nanocrystalline indium tin oxide thin films. Mater. Sci. Eng. B 2015, 199, 37. [CrossRef]

24. Shao, L.X.; Chang, K.H.; Hwang, H.L. Zinc sulfide thin films deposited by RF reactive sputtering for photovoltaic applications. Appl. Surf. Sci. 2003, 15, 305. [CrossRef]

25. Zhang, D.; Tavakoliyaraki, A.; Wu, Y.; Van Swaaij, R.; Zeman, M. Influence of ITO deposition and post annealing on HIT solar cell structures. Energy Procedia 2011, 8, 207-213. [CrossRef]

26. McEvoy, A.; Castaner, L.; Markvart, T. Solar Cells Materials, Manufacture and Operation; Academic Press: London, UK, 2013. 